\title{
Empirical Evidence on Long-term Care Insurance Purchase in France*
}

\author{
Christophe Courbage ${ }^{\mathrm{a}}$ and Nolwenn Roudaut ${ }^{\mathrm{b}}$ \\ ${ }^{\mathrm{a}}$ The Geneva Association, 53 route de Malagnou, $\mathrm{CH}$ - 1208 Geneva. \\ E-mail: christophe_courbage@genevaassociation.org \\ 'IREA, Université de Bretagne Sud, 8 rue Montaigne, FR - 56017 Vannes. \\ E-mail: nolwenn.roudaut@univ-ubs.fr
}

While many theoretical arguments have been proposed to explain the decision whether to purchase long-term care (LTC) insurance, little work has been done to study this phenomenon empirically. This article uses cross-sectional data from the newly developed SHARE (Survey of Health, Ageing, and Retirement in Europe) database to estimate the determinants of the probability of purchasing LTC insurance in France. We show that LTC insurance is purchased not only to preserve bequests and to financially protect families in the event of disability, but also to reduce the burden on potential informal care givers. Risk behaviours as well as experience of disability also play a significant role in explaining the demand for LTC insurance in France.

The Geneva Papers (2008) 33, 645-658. doi:10.1057/gpp.2008.30

Keywords: long-term care; insurance; bequest; informal care

\section{Introduction}

The ageing of populations in most industrialised countries is accompanied by an increase in the need for long-term care (LTC). LTC is a mix of social and health care provided on a daily basis, formally or informally, at home or in institutions, to people suffering from a loss of mobility and autonomy in their activity of daily living. Although loss of autonomy may occur at any age, its frequency rises with age. For instance, in France today, the probability of any given 65-year-old individual needing LTC in the future is estimated to be in excess of 40 per cent. ${ }^{1}$ At the same time, the number of informal caregivers is decreasing. This trend is attributed to the decomposition of the family unit, the distancing of children from their parents, and the increase in women's employment rates. Furthermore, low rates of public LTC coverage suggest that the financial consequences of dependency could be catastrophic, even resulting in ruin, for a number of elderly people and their families. ${ }^{2}$

For some decades now, insurance companies have been offering LTC insurance contracts. The policy-holders pay a premium and, should they suffer from physical difficulties in the activities of daily living or from cognitive difficulties, requiring LTC,

\footnotetext{
* Useful comments of participants at the 2008 meeting of the Swiss Society of Economics and Statistics, at the 2007 conference of the French Health Economists and of two reviewers are gratefully acknowledged.

${ }^{1}$ OECD (2005).

${ }^{2}$ Assous and Mahieu (2002).
} 
646

they receive financial compensation. Market evolution strongly depends on institutional settings, and the United States and France are currently the most developed markets. Yet the demand for LTC insurance would seem relatively small in comparison to the importance of the risk of dependency and the aversion of individuals to such a risk. Several theoretical arguments have been proposed to explain the decisions whether to purchase LTC insurance.

A common explanation for the lack of LTC insurance purchasing is that individuals are inadequately informed about the products available and that they ignore lowfrequency high-severity events that have not occurred recently. ${ }^{3}$ Another explanation for the limited development of LTC insurance markets includes the phenomena of moral hazard (over-consumption of care encouraged by insurance) and of adverse selection (over-representation of bad risks in the insured population), and the fact that the interaction of public insurance programmes arguably crowds out private insurance. Intergenerational factors have also been proposed to explain the demand for LTC insurance. ${ }^{4}$ The desire to leave a bequest seems a major motive for LTC insurance. However, elderly individuals with children may decide to forego the purchase of LTC insurance due to intra-family moral hazard. Indeed, parents who prefer to receive care from their children may decline the offer to purchase insurance as this may create a disincentive for children to provide care. Yet bequests can be structured so as to provide an incentive for children to care for their elderly parents. If LTC insurance were purchased, parents could increase the sensitivity of the bequest to caregiving in order to elicit attention from children. ${ }^{5}$

While the theoretical literature on the subject is rather abundant, relatively little empirical research has been done into the factors affecting the decision to purchase coverage, and it relates almost exclusively to the situation in the United States. Sloan and Norton ${ }^{6}$ examine the relation existing between the demand for LTC insurance and, respectively, the bequest motive and expectations of future nursing home use. Although they find phenomena of adverse selection, the bequest motive does not seem to influence the demand for LTC insurance. Mellor ${ }^{7}$ shows that education, income, and wealth positively impact LTC insurance, while availability of informal care has no statistically significant effect on LTC insurance. Doerpinghaus and Gustavson ${ }^{8}$ show that nursing home expenditure levels, the relative size of the elderly population, and the nursing home population are significant explanatory factors of LTC insurance purchase in some States of the U.S. The intuition is that these variables raise the awareness among the elderly about cost and quality issues in LTC, which should reinforce the utility of LTC insurance for such individuals. Recently, Brown and Finkelstein ${ }^{9}$ have presented evidence of supply-side market failures in U.S. LTC

\footnotetext{
${ }^{3}$ Kunreuther (1978).

4 Pauly (1990).

5 Zweifel and Strüwe (1996).

${ }^{6}$ Sloan and Norton (1997).

${ }^{7}$ Mellor (2001).

${ }^{8}$ Doerpinghaus and Gustavson (2002).

${ }^{9}$ Brown and Finkelstein (2007).
} 
insurance market, such failures being explained by the characteristics and pricing of the products on offer.

The aim of this paper is to empirically study the determinants of the demand for LTC insurance on the French market using cross-sectional data from the newly developed SHARE (Survey of Health, Ageing, and Retirement in Europe) database, which deals with the health, lifestyle, and financial situation of individuals aged 50 years and over in the majority of European countries. To our knowledge, no similar study currently exists for France, mainly due to the lack of available data until recently. In addition, the French market strongly depends on the institutional settings, and results obtained from American data are not representative of the situation in France.

Firstly, based on a simple probit, we estimate the probability of an individual taking out LTC insurance. We examine whether this probability is significantly influenced by income, education, the probability of leaving a bequest, family structure, experience of dependency, risk behaviours, level of informal care, and health status. Secondly, we control for the endogeneity of informal care by using a two-stage model of the likelihood of receiving informal care. Our results suggest that LTC insurance is strongly driven by altruistic behaviours. It is purchased not only to preserve bequests and to financially protect family or relatives in the event of disability, but also to reduce the burden on potential informal caregivers. Experience of disability, as well as risk behaviours, also have a significant impact on the demand for LTC insurance in France.

The article is organised as follows: in the following section, we briefly present the financing of LTC in France; the next section is devoted to the description of the database, the variables used, and the simple probit model; the results are presented in the subsequent section; the penultimate section accounts for the endogeneity of informal care. Finally, the final section offers a conclusion.

\section{Financing LTC in France}

The public coverage of LTC is derived in France not only from a long tradition of intervention concerning social assistance, but also from the great diversity of actors and sources of financing. At the national level, the sickness insurance scheme deals with expenses concerning health care. In addition, the retirement insurance scheme allows the financing of a significant part of living expenses through means of domestic assistance. At the regional level, general councils manage the Personalised Allowance of Autonomy (APA). The APA is paid to people aged 60 or more who are no longer autonomous, regardless of their financial situation and geographical location. However, only those with a low income are exempted from the co-payment, which can represent up to 80 per cent of the total cost. This allowance is jointly funded by both central and regional governments. APA can be seen as a first step towards recognition of dependency as a new risk of life, yet public coverage remains low in comparison with the financial expenses incurred by the occurrence of dependency. ${ }^{10}$

\footnotetext{
${ }^{10}$ Public coverage represents only 30 per cent of the average cost of LTC (Ennuyer, 2006).
} 
648

Also, in addition to public coverage, private insurance has developed in France. LTC insurance contracts are individual or collective and guarantee the payment of a fixed allowance, in the form of monthly cash benefit, possibly proportional to the degree of dependency. The French market, with an annual growth close to 15 per cent, ${ }^{11}$ proves to be one of the most dynamic among the industrialised markets. Contrary to the U.S., ${ }^{12}$ public authorities do not use tax incentives to encourage the development of private LTC insurance. In France, it seems that national debates associated with the search for new solutions to cover the risk of LTC need, widely covered in the press, have increased the general public's awareness of the existence of this risk. This has supported the development of private insurance. ${ }^{13}$ It also seems that the success of the French market is explained by the choice of the products offered. Whereas U.S. insurers have launched products with service benefits (payment proportional to LTC expenditure), French insurers have turned to cash benefit products. Policy-holders would appear to prefer the freedom of cash disability benefits, even if that implies the need to organise the care themselves, to the simplicity of the service benefit. ${ }^{14}$ Yet the determinants of LTC insurance in France are not clearly identifiable; therefore, this work will try to clarify and explain the main factors influencing the demand for LTC insurance.

\section{The data and model}

\section{Data}

The SHARE is a multidisciplinary and cross-national micro-database containing information on approximately 22,000 Europeans over the age of 50 and their spouses. It includes countries from Northern Europe (Denmark and Sweden), Central Europe (Austria, Belgium, France, Germany, The Netherlands, and Switzerland), and Southern Europe (Greece, Italy, and Spain). The database contains information on health-related variables (self-reported health, physical functioning, cognitive functioning, psychological health, well-being, life satisfaction, and health-care-seeking behaviour), labour market variables (current work activity, job characteristics, opportunities to work past retirement age), economic variables (sources and composition of current income, wealth, and consumption). Other variables include education, housing, and social support variables, for instance assistance within families, informal care, transfers of income and assets, and social networks. SHARE follows the design of the U.S. Health and Retirement Study and the English Longitudinal Study of Ageing. A description of methodological issues can be found in Börsch-Supan and Jürges. ${ }^{15}$ A first wave of SHARE was developed in 2004. A second wave, updating the first, was released in 2007. This second wave is the one we are

\footnotetext{
${ }^{11}$ Kessler (2008).

12 The market for LTC insurance in the United States accounts for nearly 10 per cent of the population and is confronted to a recent decline (McNamara and Lee, 2004).

13 Durand and Taleyson (2003).

14 Ibid.

15 Börsch-Supan and Jürges (2005).
} 
using. The sample for France contains 3,193 individuals. Missing values for some variables and a restriction to individuals aged 50 and over have left us with 2,530 observations.

\section{Dependent variable}

SHARE asks various questions on the terms of health insurance and, in particular, on insurance covering LTC. The question of special interest to us is "Do you have any supplementary or private health insurance for one of the following types of care?" A list of different types of care is then proposed. The answers corresponding to insurance covering LTC in a nursing home, nursing care at home in case of chronic disease or disability, and home help for assistance with daily activities are chosen to define LTC insurance. In the sample, insurance for one of these three types of care is subscribed by 26,49 , and 12.5 per cent, respectively, of the individuals. As these forms of care correspond to the common definition of LTC, we considered that an individual has LTC insurance if he has subscribed to at least one of these three types of care. This is the case for 52.7 per cent of individuals in the sample.

The probability of taking out LTC insurance is estimated through a simple probit. We examine whether this probability is significantly influenced by the explanatory variables mentioned thereafter.

\section{Explanatory variables}

Table 1 summarises the set of variables used in our analysis. We consider family structure, income, bequest, risk perception, risk behaviour, informal care, age, and health level as the main explanatory variables.

Married persons may feel the need to protect their partner from the financial burden of impoverishment due to LTC expenses and could then demand more insurance. The role of children is more complex, as explained previously, because they are subject to intra-family moral hazard.

Income is a relatively difficult variable to obtain for this age group since many individuals have already left the labour market. Nevertheless, SHARE provides the users with a generated variable for income. This variable represents the total household gross income. We created five classes of income to allow a non-linear modelling of the effect of income on the demand for insurance.

SHARE contains information about the amount of inheritance individuals intend to leave to their descendants. We have created three indicative variables reflecting the probable amount individuals hope to leave as inheritance. Households are divided into three groups: those who have no inheritance to leave, those who estimate leaving an inheritance of less than $€ 150,000$, and those who estimate leaving an inheritance of at least $€ 150,000$.

Being confronted with the risk of needing LTC should raise awareness about this risk and could modify behaviours in terms of LTC insurance. We consider two types of variables that reflect this phenomenon: providing or having provided informal care to a family member, and having personally experienced hospitalisation or serious 
Table 1 SHARE sample variable means and definitions $(n=2,530)$

\begin{tabular}{|c|c|c|c|c|c|}
\hline Variable & Definition & & $\begin{array}{l}\text { Non- } \\
\text { insured }\end{array}$ & Insured & \\
\hline LTCI & $\begin{array}{l}=1 \text { if respondent reports having private } \\
\text { long-term care insurance (LTC in } \\
\text { nursing home, nursing care at home, } \\
\text { home help) }\end{array}$ & $52.7 \%$ & $0 \%$ & $100 \%$ & \\
\hline Female & $=1$ if respondent is female & $54.8 \%$ & $54.6 \%$ & $54.9 \%$ & \\
\hline Age & Age at interview & 64.48 & 64.88 & 64.13 & $*$ \\
\hline Nb_child & Number of children & 2.29 & 2.21 & 2.36 & $* *$ \\
\hline Married & $=1$ if respondent is married & $66.0 \%$ & $64.0 \%$ & $67.8 \%$ & $* *$ \\
\hline Single & $=1$ if respondent is single & $6.7 \%$ & $8.4 \%$ & $5.2 \%$ & $* * *$ \\
\hline Divorced & $=1$ if respondent is divorced & $10.9 \%$ & $11.7 \%$ & $10.2 \%$ & \\
\hline Widow & $=1$ if respondent is widowed & $16.4 \%$ & $16.0 \%$ & $16.8 \%$ & \\
\hline Educ level 0 & $\begin{array}{l}=1 \text { if respondent has no primary } \\
\text { education }\end{array}$ & $19.4 \%$ & $20.3 \%$ & $18.7 \%$ & \\
\hline Educ level 1 & $\begin{array}{l}=1 \text { if respondent has primary school level } \\
\text { education }\end{array}$ & $25.7 \%$ & $26.2 \%$ & $25.2 \%$ & \\
\hline Educ level 2 & $=1$ if respondent has GCSE level & $9.6 \%$ & $9.9 \%$ & $9.4 \%$ & \\
\hline Educ level 3 & $\begin{aligned}= & 1 \text { if respondent has technical school } \\
& \text { certificate }\end{aligned}$ & $22.1 \%$ & $19.2 \%$ & $24.6 \%$ & $* * *$ \\
\hline Educ level 4 & $=1$ if respondent has technical diploma & $3.2 \%$ & $2.8 \%$ & $3.7 \%$ & \\
\hline Educ level 5 & $=1$ if respondent has $\mathrm{A}$ level & $19.9 \%$ & $21.4 \%$ & $18.5 \%$ & $*$ \\
\hline Income & Household gross income & 48,995 & 51,707 & 46,563 & $* *$ \\
\hline Low inheritance & $\begin{array}{l}=1 \text { if the household expects not to leave } \\
\text { an inheritance to his descendants }\end{array}$ & $15.8 \%$ & $18.9 \%$ & $13.0 \%$ & $* * *$ \\
\hline $\begin{array}{l}\text { Medium } \\
\text { inheritance }\end{array}$ & $\begin{array}{l}=1 \text { if the household expects to leave an } \\
\text { inheritance of less than } € 150,000 \text { to his } \\
\text { descendants }\end{array}$ & $46.8 \%$ & $47.4 \%$ & $46.2 \%$ & \\
\hline High inheritance & $\begin{array}{l}=1 \text { if the household expects to leave an } \\
\text { inheritance of at least of } € 150,000 \text { to his } \\
\text { descendants }\end{array}$ & $37.5 \%$ & $33.7 \%$ & $40.8 \%$ & $* * *$ \\
\hline Life insurance & $\begin{aligned}= & 1 \text { if the household holds a life insurance } \\
& \text { policy }\end{aligned}$ & $29.3 \%$ & $26.5 \%$ & $31.9 \%$ & $* * *$ \\
\hline Hospital & $\begin{aligned}= & 1 \text { if respondent has been hospitalised } \\
& \text { recently }\end{aligned}$ & $14.5 \%$ & $12.3 \%$ & $16.5 \%$ & $* *$ \\
\hline Very good health & $\begin{aligned}= & 1 \text { if respondent reports health status as } \\
& \text { very good }\end{aligned}$ & $8.3 \%$ & $8.9 \%$ & $7.7 \%$ & \\
\hline Good health & $\begin{aligned}= & 1 \text { if respondent reports health status as } \\
& \text { good }\end{aligned}$ & $15.6 \%$ & $15.9 \%$ & $15.3 \%$ & \\
\hline Average health & $\begin{array}{l}=1 \text { if respondent reports health status as } \\
\text { average }\end{array}$ & $44.5 \%$ & $45.4 \%$ & $43.6 \%$ & \\
\hline Bad health & $\begin{array}{l}=1 \text { if respondent reports health status as } \\
\text { bad }\end{array}$ & $23.4 \%$ & $21.5 \%$ & $25.5 \%$ & $* *$ \\
\hline Very bad health & $\begin{array}{l}=1 \text { if respondent reports health status as } \\
\text { very bad }\end{array}$ & $8.3 \%$ & $8.4 \%$ & $8.2 \%$ & \\
\hline LTI & $\begin{aligned}= & 1 \text { if respondent suffers from chronic or } \\
& \text { long-term conditions }\end{aligned}$ & $50.7 \%$ & $48.0 \%$ & $53.2 \%$ & $* * *$ \\
\hline
\end{tabular}


Table 1 Continued

\begin{tabular}{|c|c|c|c|c|c|}
\hline Variable & Definition & & $\begin{array}{l}\text { Non- } \\
\text { insured }\end{array}$ & Insured & \\
\hline LTA1 & $\begin{array}{l}=1 \text { if respondent has been strongly } \\
\text { limited during the last } 6 \text { months in } \\
\text { normal activities due to health problems }\end{array}$ & $14.8 \%$ & $12.9 \%$ & $16.4 \%$ & $* *$ \\
\hline BMI level 1 & $=1$ if respondent is underweight & $2.0 \%$ & $2.5 \%$ & $1.5 \%$ & $*$ \\
\hline BMI level 2 & $=1$ if respondent is of normal weight & $43.4 \%$ & $46.0 \%$ & $41.1 \%$ & $* *$ \\
\hline BMI level 3 & $=1$ if respondent is overweight & $38.6 \%$ & $37.1 \%$ & $39.9 \%$ & \\
\hline BMI level 4 & $=1$ if respondent is obese & $16.0 \%$ & $14.4 \%$ & $17.5 \%$ & $* *$ \\
\hline Smoker & $=1$ if respondent smokes & $14.4 \%$ & $15.3 \%$ & $13.6 \%$ & \\
\hline Past-smoker & $=1$ if respondent gave up smoking & $27.7 \%$ & $26.3 \%$ & $28.9 \%$ & \\
\hline Alcohol & $\begin{array}{l}=1 \text { if respondent drinks at least two } \\
\text { glasses of alcohol for } 5 \text { or } 6 \text { days per } \\
\text { week }\end{array}$ & $23.0 \%$ & $21.8 \%$ & $24.0 \%$ & \\
\hline Chronic2 & $\begin{aligned}= & 1 \text { if respondent reports at least } 2 \text { chronic } \\
& \text { conditions }\end{aligned}$ & $42.6 \%$ & $41.4 \%$ & $43.6 \%$ & \\
\hline Symptom 2 & $\begin{aligned}= & 1 \text { if respondent reports at least } 2 \\
& \text { symptoms }\end{aligned}$ & $39.8 \%$ & $39.2 \%$ & $40.4 \%$ & \\
\hline Physical activity & $\begin{array}{l}=1 \text { if respondent does not practice any } \\
\text { activity that implies substantial or } \\
\text { moderate physical effort }\end{array}$ & $12.1 \%$ & $12.3 \%$ & $11.5 \%$ & \\
\hline Mobility & $\begin{array}{l}\text { Number of mobility difficulties in daily } \\
\text { activities (walking, climbing stairs, etc.) }\end{array}$ & 1.37 & 1.32 & 1.42 & \\
\hline ADL & $\begin{array}{l}\text { Number of difficulties in activities of daily } \\
\text { living (dressing, Washing, Eating, etc.) }\end{array}$ & 0.17 & 0.16 & 0.18 & \\
\hline IADL & $\begin{array}{l}\text { Number of difficulties in instrumental } \\
\text { activities of daily living (phoning, using a } \\
\text { map, taking medicines, etc.) }\end{array}$ & 0.30 & 0.31 & 0.28 & \\
\hline Help_Provided & $\begin{array}{l}=1 \text { if respondent has provided help to a } \\
\text { relative (father, mother, brother/sister, } \\
\text { past-spouse, uncle/aunt) }\end{array}$ & $14.1 \%$ & $12.1 \%$ & $15.9 \%$ & $* * *$ \\
\hline Help_Received & $\begin{array}{c}=1 \text { if the household has received help } \\
\text { from a descendant (children, step } \\
\text { children, grand children, nephew) }\end{array}$ & $9.8 \%$ & $9.1 \%$ & $10.4 \%$ & \\
\hline One daughter & $=1$ if respondent has at least one daughter & $68.4 \%$ & $67.4 \%$ & $69.3 \%$ & \\
\hline
\end{tabular}

${ }^{\text {a }}$ During the last 12 months.

*Difference in means statistically different from 0 at the 10 per cent level of significance.

**Difference in means statistically different from 0 at the 5 per cent level of significance.

*** Difference in means statistically different from 0 at the 1 per cent level of significance.

illness in the past. These two scenarios may raise awareness of an individual's responsibility regarding the risk of potentially needing LTC in the future.

In order to be able to detect potential phenomena of adverse selection, it is necessary to identify those running the greatest risk of becoming dependent. A high body mass index, as well as the consumption of alcohol and tobacco, may serve as indicators of risky behaviour. ${ }^{16}$

\footnotetext{
${ }^{16}$ Lafortune and Balestat (2007).
} 
652

So as to test for the influence of intra-family moral hazard, we need to know how the presence of informal care influences the demand for LTC insurance. Informal care corresponds to the household receiving help for personal care, domestic, and administrative help from a descendant.

Since we do not have any indication on the level of insurance premiums, age could be regarded as a proxy for the price of insurance. One might expect that age is negatively correlated with the probability of purchasing insurance since insurance premiums found on the market usually increase importantly with age.

We also control for the level of education of individuals as well as their health status (chronic diseases, level of activities, symptoms).

\section{Results}

The results from the probit regression are presented in Table 2. The number of children and the expected level of bequests are introduced successively into the model (columns 1, 2, and 3). The stability of the parameters estimated between the various specifications is an indicator of the robustness of our results.

The preliminary results show that income has a non-linear bell-shaped effect on the demand for LTC insurance. ${ }^{17}$ Very low-income people take out little insurance cover, which might be explained by the existence of a higher public coverage for the lowest incomes. It is mostly middle-income people who take out LTC insurance. Then, from a certain level of income, the demand for insurance is decreasing with respect to income. For high-income people, insurance is an inferior good. ${ }^{18}$ This would be explained by the fact that individual risk aversion decreases with wealth. ${ }^{19}$

The demand for LTC insurance is also strongly related to the amount of inheritance. Indeed, an individual who has a high inheritance to leave to his children is more likely to purchase LTC insurance. This suggests that LTC insurance is purchased in order to preserve the inheritance, thus demonstrating some form of altruistic behaviour.

Such altruistic behaviour seems to be confirmed by the fact that the probability of having LTC insurance is higher for married individuals and those with children. LTC insurance would be demanded not to protect oneself from the financial consequences of dependency, but rather to protect family and relatives against the financial risks of becoming dependent in the future.

Receiving informal care influences positively the demand for LTC insurance, suggesting that intra-family hazard has little impact on the demand for insurance. Yet this has to be put in perspective since children are the main informal caregivers and

\footnotetext{
${ }^{17}$ We suppose that the income effect is linear within classes: for each class a binary variable and a level variable are introduced. Five classes of income are considered. As far as 10 parameters are involved, the global effect of income is difficult to interpret at first glance. Computing the function allows one to determine that income has an inverse U-shaped effect on LTC probability, with a maximum at $€ 25,000$.

18 Mossin (1968).

${ }^{19}$ Such behaviour is known as DARA (Decreasing Absolute Risk Aversion). A usual way to test for DARA is to show that risky investment increases with wealth. Unfortunately the SHARE database does not enable us to test this assumption.
} 
Christophe Courbage and Nolwenn Roudaut Empirical Evidence on Long-term Care Insurance Purchase in France

Table 2 Dependent variable: having long-term care insurance (LTCI) (except column (5): Help_Received).

\begin{tabular}{|c|c|c|c|c|c|c|}
\hline & (1) & (2) & (3) & (4) & (5) & (6) \\
\hline Female & $0.095 * * *$ & $0.097 * * *$ & $0.105^{* * *}$ & $0.101 * * *$ & $0.687 * * *$ & 0.039 \\
\hline Age & 0.010 & 0.009 & 0.010 & 0.015 & & $0.032 * * *$ \\
\hline Age (square) & -0.000 & -0.000 & -0.000 & $-0.000 * *$ & & $-0.000^{* * *}$ \\
\hline Nb_child & & $0.035^{* * *}$ & $0.043^{* * *}$ & $0.041 * * *$ & $0.011 * * *$ & $0.050 * * *$ \\
\hline Single & $-0.285^{* * *}$ & $-0.219 * * *$ & $-0.171^{* * *}$ & $-0.170 * * *$ & & $-0.125^{* * *}$ \\
\hline Divorced & $-0.137^{* *}$ & $-0.126^{* *}$ & -0.090 & -0.091 & & $-0.095^{* * *}$ \\
\hline Widow & $0.072 * *$ & $0.075^{* *}$ & $0.091 * * *$ & $0.073 * * *$ & & 0.085 \\
\hline \multicolumn{7}{|l|}{ Ref $=$ Married } \\
\hline Educ level 0 & 0.037 & $0.059 * * *$ & 0.029 & $0.035^{* * *}$ & 0.084 & -0.001 \\
\hline Educ level 2 & 0.032 & 0.057 & 0.027 & 0.040 & $-0.474 * * *$ & -0.016 \\
\hline Educ level 3 & $0.174 * * *$ & $0.196 * * *$ & $0.167^{* * *}$ & $0.176^{* * *}$ & $-0.740^{* * *}$ & $0.123^{* * *}$ \\
\hline Educ level 4 & $0.267 * * *$ & $0.289 * * *$ & $0.238 * * *$ & $0.240 * * *$ & $0.426^{* * *}$ & $0.169^{*}$ \\
\hline Educ level 5 & 0.030 & 0.053 & -0.008 & -0.002 & $-0.192 * *$ & $-0.086^{* * *}$ \\
\hline \multicolumn{7}{|l|}{ Ref $=$ Educ level 1} \\
\hline Income $1(\leqslant € 12500)$ & $0.033 * * *$ & $0.035 * * *$ & $0.033^{* * *}$ & $0.031 * * *$ & $0.049 * *$ & $0.043^{* * *}$ \\
\hline Income 2 ( ]12 500; 25000$])$ & $0.022 * * *$ & $0.022 * * *$ & $0.020 * * *$ & $0.020 * * *$ & -0.019 & $0.029 * * *$ \\
\hline Income 3(] $25000 ; 50000])$ & -0.003 & -0.002 & $-0.004 * *$ & $-0.004 * *$ & -0.030 & -0.002 \\
\hline Income 4(] $50000 ; 75000])$ & -0.010 & -0.009 & -0.009 & -0.009 & $-0.026^{* * *}$ & -0.013 \\
\hline Income $5(>75000)$ & $-0.000^{* *}$ & $-0.000 * *$ & -0.000 & -0.000 & $0.005^{* *}$ & -0.001 \\
\hline Income 1 (binary) & $-0.210 * * *$ & $-0.223 * * *$ & $-0.147 * * *$ & $-0.147 * * *$ & 0.759 & $-0.222 * * *$ \\
\hline Income 2 (binary) & $-0.223^{* *}$ & $-0.210 * *$ & $-0.150 * *$ & $-0.149 * *$ & $1.291 * * *$ & $-0.326^{* * *}$ \\
\hline Income 3 (binary) & $0.264 * * *$ & $0.260 * * *$ & $0.348 * * *$ & $0.347 * * *$ & $1.429^{*}$ & $0.278 * * *$ \\
\hline Income 4 (binary) & 0.702 & 0.668 & 0.661 & 0.652 & $2.087 * * *$ & 0.834 \\
\hline \multicolumn{7}{|l|}{ Ref $=$ Income 5 (binary) } \\
\hline Low inheritance & & & $-0.393 * * *$ & $-0.392 * * *$ & $0.199 * *$ & $-0.369^{* * *}$ \\
\hline Average inheritance & & & $-0.161 * * *$ & $-0.162 * * *$ & $0.276^{* *}$ & $-0.230^{* * *}$ \\
\hline \multicolumn{7}{|l|}{ Ref $=$ High inheritance } \\
\hline Life insurance & $0.163^{* * *}$ & $0.166^{* * *}$ & $0.122^{* * *}$ & $0.126^{* * *}$ & & $0.125^{*}$ \\
\hline Hospital & 0.139 & 0.138 & 0.131 & 0.132 & & 0.155 \\
\hline Very good health & -0.036 & -0.035 & -0.049 & -0.054 & & -0.035 \\
\hline Good health & 0.034 & 0.035 & 0.027 & 0.025 & & 0.042 \\
\hline Bad health & $0.087 * * *$ & $0.089 * * *$ & $0.102 * * *$ & $0.100 * * *$ & & $0.063^{*}$ \\
\hline Very bad health & -0.044 & -0.038 & -0.019 & -0.016 & & -0.070 \\
\hline \multicolumn{7}{|l|}{ Ref $=$ Average health } \\
\hline LTI & $0.114^{* * *}$ & $0.115 * * *$ & $0.111^{* * *}$ & $0.105 * * *$ & & $0.109 * * *$ \\
\hline LTA1 & $0.181^{* * *}$ & $0.182 * * *$ & $0.191 * * *$ & $0.190 * * *$ & & $0.231 * * *$ \\
\hline BMI level 1 & -0.215 & -0.212 & -0.216 & -0.226 & & -0.069 \\
\hline BMI level 3 & $0.094 * * *$ & $0.090 * *$ & $0.100 * * *$ & $0.101 * * *$ & & $0.100 * * *$ \\
\hline BMI level 4 & 0.149 & 0.137 & 0.155 & 0.151 & & 0.144 \\
\hline Ref $=$ BMI level 2 & & & & & & \\
\hline
\end{tabular}


Table 2 Continued

\begin{tabular}{|c|c|c|c|c|c|c|}
\hline & (1) & (2) & (3) & (4) & (5) & (6) \\
\hline Smoker & -0.028 & -0.031 & -0.027 & -0.024 & & -0.005 \\
\hline Past smoker & 0.040 & 0.043 & 0.044 & 0.047 & & 0.053 \\
\hline Alcohol & $0.110^{* * * *}$ & $0.114 * * *$ & $0.108 * * *$ & $0.109 * * *$ & & $0.103 * * *$ \\
\hline Chronic2 & -0.028 & -0.032 & -0.033 & -0.036 & & -0.046 \\
\hline Symptom 2 & -0.054 & $-0.058^{*}$ & -0.061 & -0.062 & & -0.012 \\
\hline Physical activity & -0.087 & -0.088 & -0.060 & -0.059 & & -0.037 \\
\hline Mobility & $0.013 * * *$ & $0.012 * * *$ & $0.012 * *$ & $0.012 * * *$ & & 0.021 \\
\hline ADL & $0.040^{* *}$ & $0.046^{* * *}$ & $0.050 * * *$ & $0.051 * * *$ & & $0.279 * * *$ \\
\hline IADL & $-0.044^{*}$ & $-0.049^{*}$ & $-0.044^{*}$ & $-0.054^{*}$ & & $-0.090^{* * *}$ \\
\hline One daughter & & & & & $0.577 * * *$ & \\
\hline Help_Provided & $0.168 * *$ & $0.177 * *$ & $0.179 * * *$ & $0.177 * * *$ & & $0.133 * * *$ \\
\hline Help_Received & & & & $0.152 * *$ & & \\
\hline Prediction (Help_Received) & & & & & & $0.171 * * *$ \\
\hline Constant & -0.570 & -0.644 & -0.575 & -0.718 & $-2.559 * * *$ & $-1.128 * * *$ \\
\hline Observations & 2,530 & 2,530 & 2,530 & 2,530 & 541 & 1,989 \\
\hline
\end{tabular}

Robust standard errors using White correction. Adjusted for clustering at the household level. *Significant at 10 per cent; **Significant at 5 per cent; ***Significant at 1 per cent.

their behaviour can be influenced by the level of insurance. To integrate this bias, we propose an extension of our model in the next section.

Having provided informal care to relatives positively affects the probability of contracting LTC insurance. This result is rather intuitive in the sense that such experience should raise awareness about LTC risk. Having been recently hospitalised or having suffered a serious illness also seems to positively influence the probability of purchasing LTC insurance. These findings conform with the results of work carried out on the role of information and on the perception of risks in decision-making processes. Having provided informal care or having suffered from serious illness encourages individuals to modify their perception with regard to their health and LTC risks. Shocks on health or serious experience of illness are often recognised as a source of information that can lead people to modify their behaviour and their economic decisions. $^{20}$

It also seems that potential phenomena of adverse selection occur within the market of LTC insurance, in that high-risk individuals tend to have a higher probability of purchasing insurance than others. Indeed, our findings show that the levels of body mass index as well as alcohol consumption, known as high-risk factors of dependency, ${ }^{21}$ positively influence the probability of purchasing LTC insurance. Adverse selection also seems to be confirmed by the fact that individuals who estimate

\footnotetext{
${ }^{20}$ Sloan et al. (2003).

${ }^{21}$ Lafortune and Balestat (2007).
} 
their current health to be bad present a higher probability of purchasing LTC insurance.

\section{Endogeneity of informal care}

The results of the probit regression presented in the preceding section show that the probability of having LTC insurance increases with the level of informal care received. However, children have the characteristic of being the main providers of informal care and their behaviour can be influenced by the level of insurance.

As underlined by Mellor, ${ }^{22}$ there might exist a phenomenon of endogeneity of informal care in the sense that the supply of informal care might depend on LTC insurance coverage. Indeed, people receiving informal care from a child can precisely be those who lack insurance coverage. Moreover, in the presence of intra-family moral hazard, having LTC insurance could encourage children to reduce or substitute their help, current or future, by formal care covered by insurance. To address these concerns, one possibility is to follow Mellor ${ }^{23}$ by estimating a bivariate probit model so as to test the causality link between the supply of informal care and insurance. ${ }^{24}$

Another possibility is to develop projections based on the estimation of an explanatory model of the probability of receiving informal care for people in situations of dependence. As informal care can only be provided to people who need it, we consider the sub-sample of the 541 individuals who find themselves in a situation where they need help. ${ }^{25}$ Table 3 shows that 26 per cent of these people receive help from their descendants. We estimate on this sub-sample a probit model to explain the probability of receiving help from descendants. Results are given in column 5 of Table 2.

In order to be able to project this model to those who may need help in the future ${ }^{26}$ it is necessary to use in the probit only time-invariant explanatory variables. As an illustration, the older an individual, the higher the probability that he will need help and thus will receive help today from his descendants. Thus, introducing the variable of age as an explanatory variable of the probability of receiving informal help could lead to an underestimation of the predicted probability of receiving informal help in the future for the youngest people. In the same way, we eliminate the variables strongly related to the risk of disability and to the need for informal care such as marital status, level of health, etc. The explanatory variables, considered in the model of prediction of the probability of receiving informal care, are then gender, level of education, characteristics of the children, income, and level of expected inheritance. The estimated probability of receiving informal care is then introduced into the

\footnotetext{
${ }^{22}$ Mellor (2001).

23 Ibid.

${ }^{24}$ See Courbage and Roudaut (2007).

${ }^{25}$ Individuals reporting at least three mobility difficulties in activities of daily living due to physical or health problems (mobility variable). The activities considered are, for example, walking on a short distance, remaining seated during two hours, leaning, kneeling or squatting, etc.

${ }^{26}$ That is, for the $1,898(=2,530-541)$ individuals who do not need help today.
} 
Table 3 Help received from descendants in activities of daily living

\begin{tabular}{lccr}
\hline & $\begin{array}{c}\text { Received help } \\
\text { from descendants }\end{array}$ & $\begin{array}{c}\text { No help from } \\
\text { descendants }\end{array}$ & Total \\
\hline Limited in mobility activities of daily living & $140(26 \%)$ & $401(74 \%)$ & $541(100 \%)$ \\
Not limited in mobility activities of daily living & $108(5 \%)$ & $1,881(95 \%)$ & $1,989(100 \%)$ \\
Total & 248 & 2,282 & 2,530 \\
\hline
\end{tabular}

equation of the demand for insurance (column 6, Table 2). This equation is estimated on the sub-sample of those who are not in a position to need help today.

Results from the simple probit of the previous section are confirmed. Moreover, we find that the probability of purchasing LTC insurance increases for those who have a higher probability of receiving informal care should the need arise in the future. An explanation is that LTC insurance would be purchased to reduce the burden on potential informal caregivers. Indeed, several studies suggest that providing informal care may have a negative effect on the informal caregiver's health. ${ }^{27}$ Formal care covered by insurance would replace informal care and would avoid strain on the informal caregiver's health. It would confirm that demand for LTC insurance is strongly driven by altruistic behaviour, and is not limited by possible phenomena of intra-family moral hazard.

\section{Conclusion}

While many theoretical arguments have been proposed to explain the decision whether to purchase LTC insurance, little work has been done to study these phenomena empirically, and it almost exclusively relates to the United States. This article uses cross-sectional data from the newly developed SHARE database in order to estimate the determinants of the probability of purchasing LTC insurance in France. Firstly, based on a simple probit, we estimate the probability of having LTC insurance. Secondly, we control for the endogeneity of informal care by using a two-stage model of the likelihood of receiving informal care.

The results obtained from French data differ from those obtained from American data. First of all, income has a non-linear bell-shaped effect on the demand for LTC insurance. This first result is consistent with the view that providing public coverage for low-income individuals crowds out private insurance.

Furthermore, it seems that the demand for LTC insurance would be, above all, driven by altruistic behaviour. It would not necessarily be demanded to protect oneself from the financial consequences of the risk of dependency, but rather to protect one's family against the risk of becoming dependent in the future. Three arguments bring us to this conclusion. Firstly, the demand for LTC insurance increases with the

\footnotetext{
${ }^{27}$ For example, Schulz and Beach (1999).
} 
probability of leaving an inheritance. As suggested by Pauly, ${ }^{28}$ LTC insurance is purchased to protect and preserve the inheritance to be transmitted. Secondly, the fact that an individual lives with a partner, as well as the number of children, is positively associated with LTC insurance. Insurance would be purchased to protect family and relatives against the financial risk of becoming dependent in the future. Thirdly, individuals with a higher probability of receiving informal care, should the need arise in the future, also have a higher probability of purchasing LTC insurance. Insurance would be perceived as a way to reduce the burden on potential informal caregivers. Such results lead us to think that the French LTC insurance market is not limited by phenomena of intra-family moral hazard, which could be another explanation of its dynamism.

Experience of disability seems also to drive the demand for LTC insurance since having provided informal care to relatives positively affects the probability of contracting LTC insurance. These results conform with the work carried out on the role of information and perception of risks in decision-making processes. Shocks on health or experience of illness are often recognised as a source of information that can lead people to modify their behaviour and their economic decision. ${ }^{29}$

It also seems that phenomena of adverse selection occur within the market of LTC insurance in the sense that high-risk individuals tend to have more insurance than others.

Nevertheless, these phenomena need to be considered with caution, since we do not have any data on the characteristics of the products offered, or on risk aversion behaviours, characteristics that strongly condition the demand for LTC insurance. Combining market data and individual data would make it possible to refine our results considerably and should constitute the object of future research.

\section{References}

Assous, L. and Mahieu, R. (2002) 'L'assurabilité de la dépendance et sa prise en charge par le secteur privé: une mise en perspective internationale', Revue Economique 53: 887-912.

Börsch-Supan, A. and Jürges, H. (eds) (2005) The Survey of Health, Ageing and Retirement in Europe Methodology, Mannheim Research Institute for the Economics of Aging, University of Mannheim, Mannheim.

Brown, J. and Finkelstein, A. (2007) 'Why is the market for long-term care insurance so small?', Journal of Public Economics 91: 1967-1991.

Courbage, C. and Roudaut, N. (2007) La demande d'assurance dépendance: une étude empirique pour la France, presented at Journées des Economistes de la Santé, 7 December, 2007, Lille, France.

Doerpinghaus, H.I. and Gustavson, G.G. (2002) 'Long-term care insurance purchase patterns', Risk Management and Insurance Review 5: 31-43.

Durand, R. and Taleyson, L. (2003) 'Les raisons du succès de l'assurance dépendance en France', Risques Les Cahiers de l'Assurance 55: 115-120.

Ennuyer, B. (2006) Repenser le maintien à domicile, Paris: Dunod.

Kessler, D. (2008) 'The long-term care insurance market', The Geneva Papers on Risk and Insurance - Issues and Practice 33: 33-40.

Kunreuther, H. (1978) Disaster Insurance Protection: Public Policy Lessons, New York: Wiley.

\footnotetext{
28 Pauly (1990).

${ }^{29}$ Sloan et al. (2003).
} 
Lafortune, G. and Balestat, G. (2007) Trends in severe disability among elderly people: Assessing the evidence in 12 OECD countries and the future implications, OECD Health Working Papers No.26, OECD, Paris.

McNamara, L. and Lee, N. (2004) 'Long-term care policy dropping in the U.S. from 1996 to 2000: Evidence and implications for long-term care financing', The Geneva Papers on Risk and Insurance - Issues and Practice 29: 594-604.

Mellor, J.M. (2001) 'Long-term care and nursing home coverage: Are adult children substitutes for insurance policies?', Journal of Health Economics 20: 527-547.

Mossin, J. (1968) 'Aspects of rational insurance purchasing', Journal of Political Economy 76: 553-568.

OECD (2005) Long-term Care for Older People, Paris: OECD.

Pauly, M.V. (1990) 'The rational nonpurchase of long-term care insurance', Journal of Political Economy 98 : $153-168$.

Schulz, R. and Beach, S.R. (1999) 'Caregiving as a risk factor for mortality: The caregiver health effects study', Journal of American Medical Association 282: 2215-2219.

Sloan, F.A. and Norton, E.C. (1997) 'Adverse selection, bequests, crowding out, and private demand for insurance: Evidence from the long-term care insurance market', Journal of Risk and Uncertainty 15: 201-219.

Sloan, F.A., Smith, V.K. and Taylor, D.H. (2003) The Smoking Puzzle - Information, Risk Perception and Choice, Cambridge, MA: Harvard University Press.

Zweifel, P. and Strüwe, W. (1996) 'Long-term care insurance and bequests as instruments for shaping intergenerational relationships', Journal of Risk and Uncertainty 12: 65-76.

\section{About the Authors}

Christophe Courbage, $\mathrm{PhD}$ in Economics, is Director of the Health and Ageing research programme at The Geneva Association and Lecturer in health economics at the University of Lausanne. His field of research focuses on insurance economics and health economics.

Nolwenn Roudaut is Assistant Professor in Economics at the University of South Brittany (France). She holds a PhD in Economics from the University of Toulouse. Her research interest is in the field of applied econometrics. 